\title{
Caregiver Engagement in Stroke Care: Opportunities and Challenges in Australia and Denmark
}

\section{OPEN ACCESS}

Edited by:

Samer A. Kharroubi, American University of

Beirut, Lebanon

Reviewed by:

Enver Envi Roshi,

University of Medicine, Tirana, Albania Nikmatul Fadilah,

Health Polytechnic of the Ministry of Health Surabaya, Indonesia

*Correspondence: Elton H. Lobo elobo@deakin.edu.au

Specialty section: This article was submitted to

Health Economics,

a section of the journal

Frontiers in Public Health

Received: 15 August 2021 Accepted: 04 November 2021 Published: 26 November 2021

Citation:

Lobo EH, Abdelrazek M, Grundy J, Kensing F, Livingston PM, Rasmussen LJ, Islam SMS and

Frolich A (2021) Caregiver

Engagement in Stroke Care: Opportunities and Challenges in Australia and Denmark.

Front. Public Health 9:758808 doi: 10.3389/fpubh.2021.758808

\begin{abstract}
Elton H. Lobo ${ }^{1,2 *}$, Mohamed Abdelrazek ${ }^{1}$, John Grundy ${ }^{3}$, Finn Kensing ${ }^{4}$, Patricia M. Livingston ${ }^{5}$, Lene J. Rasmussen ${ }^{6,7}$, Sheikh Mohammed Shariful Islam ${ }^{8}$ and Anne Frolich ${ }^{2,9}$

${ }^{1}$ School of Information Technology, Deakin University, Geelong, VIC, Australia, ${ }^{2}$ Department of Public Health, University of Copenhagen, Copenhagen, Denmark, ${ }^{3}$ Faculty of Information Technology, Monash University, Clayton, VIC, Australia, ${ }^{4}$ Department of Computer Science, University of Copenhagen, Copenhagen, Denmark, ${ }^{5}$ Faculty of Health, Deakin University, Geelong, VIC, Australia, ${ }^{6}$ Department of Cellular and Molecular Medicine, University of Copenhagen, Copenhagen, Denmark, ${ }^{7}$ Center for Healthy Aging, University of Copenhagen, Copenhagen, Denmark, ${ }^{8}$ Institute for Physical Activity and Nutrition (IPAN), Deakin University, Geelong, VIC, Australia, ${ }^{9}$ Innovation and Research Centre for Multimorbidity, Slagelse Hospital, Region Zealand, Denmark
\end{abstract}

Globally, there is a rise in incident cases of stroke, particularly in low- and middle-income countries, due to obesity-related and lifestyle risk factors, including health issues such as high cholesterol, diabetes and hypertension. Since the early 20th century, stroke mortality has declined due to proper management of the risk factors and improved treatment practices. However, despite the decline in mortality, there is an increase in the levels of disability that requires long-term support. In countries such as Australia and Denmark, where most care is provided within the community; family members, generally spouses, assume the role of caregiver, with little to no preparation that affects the quality of care provided to the person living with stroke. While past research has highlighted aspects to improve caregiver preparedness of stroke and its impact on care; health planning, recovery, and public health policies rarely consider these factors, reducing engagement and increasing uncertainty. Hence, there is a need to focus on improving strategies during recovery to promote caregiver engagement. In this study, we, therefore, try to understand the needs of the caregiver in stroke that limit engagement, and processes employed in countries such as Australia and Denmark to provide care for the person with stroke. Based on our understanding of these factors, we highlight the potential opportunities and challenges to promote caregiving engagement in these countries.

Keywords: engagement (involvement), stroke, caregiving-informal, health planning, recovery, policy and guidelines

\section{INTRODUCTION}

In the past few decades, there has been a shift in the overall global disease burden from infectious, nutritional, neonatal, and maternal causes to non-infectious diseases, with cardiovascular diseases and stroke being the predominant causes (1). Amongst cardiovascular disease and stroke, stroke remains a global health problem (2); as it is one of the leading causes of death and disability in the modern world (3). Recent data from the global burden of diseases study demonstrates that stroke accounts for $10 \%$ of deaths worldwide and $5 \%$ of disability-adjusted life-years (4). Moreover, the 
type of care provided to persons living with stroke over their lives depends on the type of stroke and its consequences (3). Over the years, $\sim 3-4 \%$ of the total health expenditure in Western counties has been spent in stroke management and care. For example, the lifetime cost in the US for stroke inpatient care, rehabilitation and follow-up per person was estimated to be around US\$ 140,048 (5). In Europe, the annual costs for stroke treatment and recovery were reported to be 27 billion euros (3). The increase in health care costs has resulted in the majority of care being conducted in the community rather than within health institutions (6) such as hospitals, rehabilitation centers etc. As a result, many family members, generally female spouses of the survivor with an average age of 58 years (7), take on the responsibility to become primary caregivers to people living with stroke (8) to ensure continuity of care.

The process of care in stroke is complex (9), and varies based on the needs, functional capabilities and support required by the person living with stroke (10). Most caregivers are often unprepared to assume their caregiving role immediately after stroke as it involves managing personal hygiene care, monitoring health and illness, administering medications, planning, and coordinating social activities and managing finances (11). Hence, several caregivers give up their dreams and aspirations to fulfill their new roles and responsibilities, which contributes to a significant burden (12). The burden of stroke caregiving is due to physical and financial strain, loneliness, confinement, and a myriad of mental and emotional strains that results in a negative health decline of the caregiver Camak (13). Furthermore, the disease is associated with long-term costs by the level of disability, with (14), estimating the cost per person in Spain to be around $€ 17,618$ per year, inclusive of informal care costs, medical costs and productivity-related costs. Another study by Taylor et al. (15) and Pucciarelli et al. (16) reported that individuals spent $\sim \$ 3,700$ on direct stroke-related (e.g., medical and non-medical) costs in Italy, with the highest cost incurred during the first 6 months of diagnosis. With most caregivers changing their work situations post-stroke, i.e., from full-time job to either a part-time job or leaving their job completely (17), there is a sudden loss of income due to the lack of work productivity. A previous study described the reduction in work productivity (18) amongst caregivers especially with older caregivers having children $<18$ years had resulted in a significant impact on the income levels (income $<\$ 25,000, P=0.02$; income between $\$ 25,000$ and $\$ 49,999, P=0.041$ vs. those individuals with an income $\geq 75,000$ ) (19). The loss of income and decreased work productivity makes it difficult to manage the financial aspects of stroke caregiving leading to additional stressors or burden (12).

Despite the burden involved in care, caregivers often want to be involved in recovery and provide tangible assistance and support for the person living with stroke (20). Engaging caregivers in the healthcare process is considered to be a key pillar in improving the effectiveness and sustainability of services (21). However, previous studies highlighted the lack of inclusion of caregivers in the recovery process; leading to the caregiver feeling neglected or abandoned by the healthcare team (22). Hence, there is a need to identify effective ways to engage the caregiver in the stroke recovery process to improve safety, quality and delivery of stroke care.

In an attempt to understand the process of engaging the caregiver in stroke within the community and recommend possible mechanisms to support the caregiver, we consider a multi-country perspective; including two developed countries (i.e., Denmark and Australia) with a publicly funded healthcare system (23). The process of stroke care in Denmark and Australia were reviewed as they have recently gained widespread public, political and academic interest for providing volunteer-based care in the community (24); with considerable differences. For example, in Denmark, people with stroke are provided professional and financial support for volunteer-based activities (25), which is not the same in Australia where people with stroke are often supported by the family members in coordination with the healthcare professional (26). Despite this difference, these volunteers may require support and training to manage the person living with stroke and perform self-support (27). Moreover, these countries allow for the individuals to access their health data; to promote self-management and care (28) that could be beneficial for long-term recovery of the patient and engagement for the caregiver (29).

\section{CAREGIVER ENGAGEMENT IN STROKE}

Caregiver engagement refers to an active partnership between the patients, families, and health care providers at various levels to improve health outcomes (30), which is central for personcentered care (31). The caregiver engagement at direct level focuses on information seeking, consultation and involvement in decision making (21), while at an organization and societal level it focuses on shared leadership required to develop better health policies (32). Active engagement by the caregiver has the potential to reduce healthcare costs, reduce burnout, improve care processes and improve patient outcomes (30). Despite these advantages in transforming healthcare delivery and policy, very little is known about strategies to engage caregivers during the stroke care trajectory effectively. Hence, in this section, we identify means to improve caregiver engagement at different levels, i.e., planning, recovery and policymaking.

\section{Healthcare System Planning and Policy Making}

Caregivers who support people affected by stroke often report proper support during in-patient care, but poor support post-discharge (33). Post-discharge, the caregivers, often feel unprepared and uncertain about the future; leading to poor health outcomes and reduced quality of care (22). Hartford et al. (34) have suggested that community services are not often coordinated efficiently. For example, in Denmark, caregivers reported a delay of up to 4 weeks in community services after discharge (35), while in Australia caregivers reported been uninformed about the care process during the transition from hospital to the community, and are unaware of the services available to them post-discharge (36); thereby impacting the continuity of care. 
The healthcare system in Denmark and Australia is focused on detecting, monitoring, diagnosing, treating and providing care to individuals based on the public health policy $(37,38)$. These policies have been developed through collaboration with different stakeholders (i.e., patient and caregivers), community leaders and representatives from governments to solve social and community problems (31). At this level, it is necessary to define the concept of engagement to ensure priorities are defined, and the program makes informed decisions. According to Hill et al. (32), the concept of caregiver engagement should focus on understanding the role of the caregiver during recovery and individual factors that may contribute to the initiation of care and maintaining partnerships. By understanding these factors, it would be possible to create a plan that (i) supports individual characteristics of the patient, (ii) ensure the preparedness of the caregiver through the generation of knowledge and skills, and (iii) determining the capacity and preparedness of the recovery team to maintain care relationships. Furthermore, when defining the health policy, one would need to include the caregiver's desire to participate in community services and decision-making practices, which would inform the healthcare professionals to reach desired health outcomes.

Both Denmark and Australia have well-defined health policy guidelines for stroke recovery. In Denmark, the health policies were defined during a stroke care reform to centralize acute stroke care (39). Based on this reform, the long-term care was provided through a collaboration between the municipality rehabilitation centers and the hospital, with an intention to move rehabilitation care to the community and reduce healthcare costs during in-patient care (39). In 2012, the reform was modified to include policies related to administrative, management and coordinating factors (39). Furthermore, this model allowed for caregivers and patients to receive physical, emotional and social health support from the municipalities to reduce burden (40). In Australia, however, stroke care policies have undergone numerous different modifications over the past decade to support and integrate the different stakeholders in stroke recovery. Some of these reforms include the inclusion of appropriate education for caregivers, strategies to support impairments of the people living with stroke and inclusion of caregivers in stroke recovery (41). Despite the policies being implemented to support caregivers in stroke; the caregivers have reported burden due to the lack of unmet needs during recovery. These unmet needs include physical and emotional strain, isolation, emotional involvement and time spent on caregiving in Denmark (42), and social isolation, change in roles and relationships, and lack of services and support in Australia (43). These unmet needs can influence on the caregiver function resulting in reduced engagement in care (21). Hence, requiring for a clear understanding of the requirements of caregivers during the design of community services and policies in stroke recovery to ensure proper support, communication and engagement practices are employed.

Hill et al. (32) defined a model to identify caregiver engagement, as shown in Figure 1. This process includes negotiation and risk assessment, awareness and information support, joint monitoring plan, shared decision making and early intervention, and making adjustments. Through the inclusion of such a process, it is possible to engage the caregiver required for healthcare planning and policy making; allowing decisionmakers to understand the needs and requirements of the caregivers in stroke recovery.

\section{Recovery}

In countries such as Denmark and Australia, the median length of stay after acute stroke is between 3 and 7 days $(26,44)$. Rehabilitation occurs within the community in the form of rehabilitation services, outpatient facility or patent's home (39, 45). Community rehabilitation of stroke focuses on improving both immediate and long-term function of the person living with stroke to increase independence; irrespective of their age, stroke type, severity, and reoccurrence (26). In this process, clinicians are often required to ensure the recovery process meets the individual needs of the person living with stroke (46). However, the quality of care post-discharge is challenging to monitor for the clinicians (39). Hence, caregivers often assume the role of supporting the patient during the disease trajectory and communicating with the healthcare professional to ensure the quality of care is maintained throughout the process of recovery $(46,47)$.

Engaging caregivers in stroke throughout the disease trajectory can be challenging (48); as the rehabilitation and decision-making process requires the caregiver to have a certain degree of knowledge and understanding of the disease (49). But due to the abrupt nature of the disease; the caregiver is often left unprepared to manage the person living with stroke in the community (43). National organizations like the Department of Social Services, Department of Health and Aging, Department of Families, Community Services and Indigenous Affairs, Department of Human Services and the Department of Veterans Affairs in Australia, and the Municipality Care Services in Denmark have a longstanding commitment toward ensuring support for the caregiver during the continuity of care through the provision of different programmes and services (40, 50). In addition to the National organization; several non-governmental organizations have been founded mostly in Australia to support individuals during stroke recoveries such as the Stroke Foundation, Carers, Care Search, Carer Gateway and My Time Peer Support Groups in Australia. Despite an abundance of services to help the caregiver in the acquisition of skills and knowledge, a majority of the caregivers are unaware of these services, and hence would need to be informed (51) to ensure better decision making and healthcare delivery.

Further, to facilitate engagement in stroke recovery; caregivers would not only need to be informed about the disease, rehabilitation, and decision-making process but would also be required to understand the model of care to ensure optimal recovery for the person living with stroke (34). The model of care is crucial to provide long-term support in the community and secondary prevention of the disease (52). In Australia, the model of care has been defined in the Acute Stroke Clinical Care Standard (53). Based on this standard, the caregiver and the person living with stroke are provided with an individualized care plan that describes the process of care including rehabilitation 


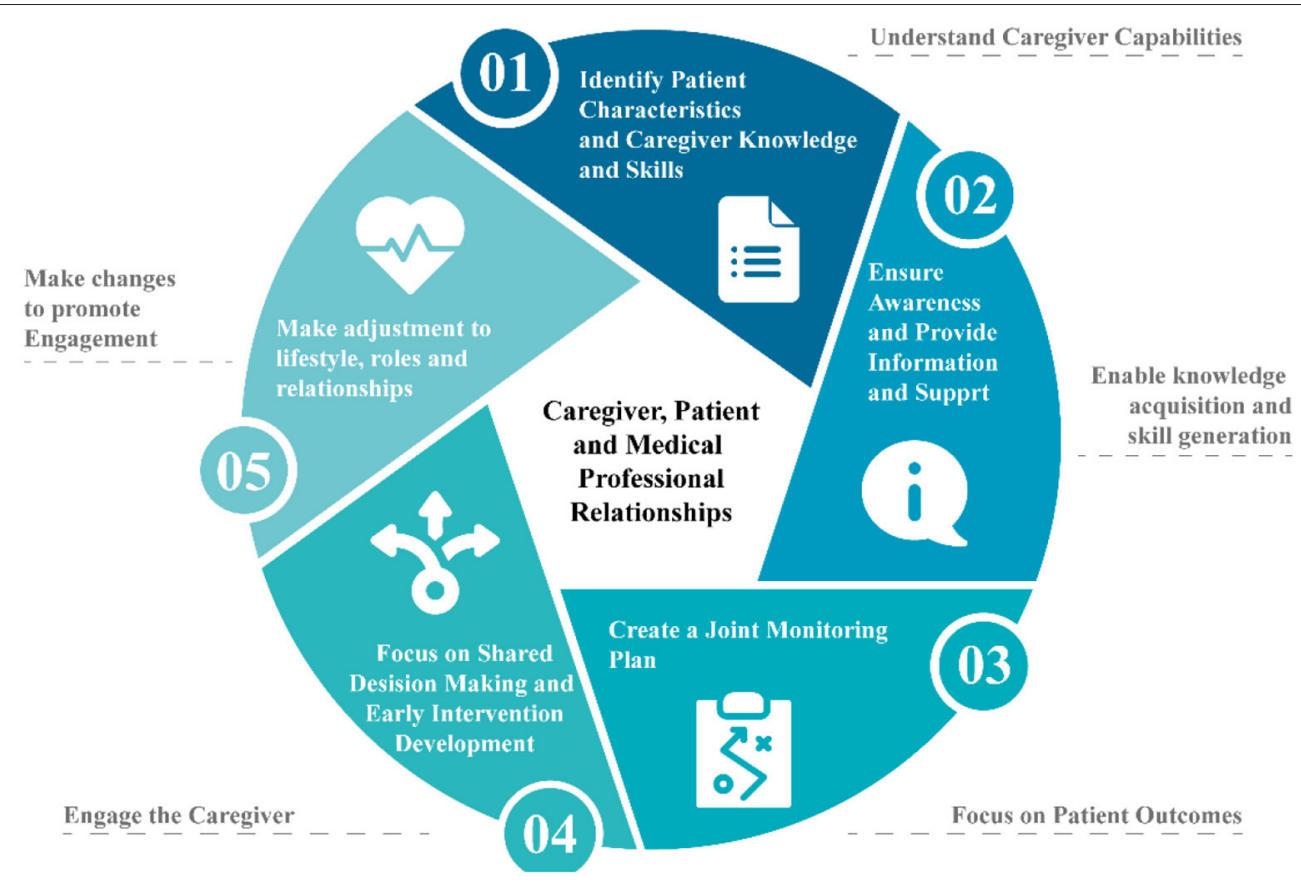

FIGURE 1 | Model for defining caregiver engagement process in health planning and policy making.

goals, medicines, and lifestyle modification required to manage risk factors. Moreover, the caregivers and person living with stroke are provided with follow-up appointments and contact details for ongoing care services (54). However, in Denmark, the process of care follows a top-to-down approach where the hospital is considered as the primary decision-makers, and the municipality follows the guidelines stated by the hospital (39). While people living with stroke and their caregiver have reported satisfaction due to the availability of professional support in the first-year post-stroke based on the model of care in Denmark. They often feel disconnected with healthcare services, as the perceived needs are not fulfilled (55). Therefore, requiring for a more integrated pathway that considers a multi-disciplinary team, including caregivers and people living with stroke to ensure share values in coordinating work and successful care (39).

\section{DISCUSSION AND IMPLICATIONS}

Findings from this perspective demonstrate both theoretical and practical implications. First, the importance of engagement in stroke caregiving has been defined as a means to promote better quality care in the community, while ensuring improved decision-making and satisfaction in care. However, this process would involve proper education, skill generation and communication to contribute to the recovery process (21). Traditionally, healthcare organizations are expected to provide support to the caregiver to facilitate development in these aspects that are evident in the literature based on Danish and Australian contexts $(40,50,56)$. However, caregivers report being unaware of these services leading to uncertainty and isolation in care (51). Moreover, very little research has been conducted in stroke caregiving engagement to understand the influence of such factors on the activities of the caregiver during the recovery trajectory. Additionally, healthcare policies in Denmark and Australia for stroke, do not account for engagement of the caregiver, and thus results in an uncertainty amongst the caregiver and the person living with stroke.

This study, highlights the need to develop the evidence to support stroke caregiving engagement by addressing the possible factors affecting the caregiver at different stages of health planning, recovery, and policymaking. Additionally, a detailed understanding of the processes involved in stroke care, available services and individual needs and experiences to create a more practical approach toward engagement with whom.

\section{Challenges in Implementing Caregiver Engagement}

Implementing caregiver engagement in stroke is not without its challenges. Lack or perceived benefit, time constraints, increased workload and lack of awareness are some of the most common challenges. These barriers can be avoided through proper education and training, which is crucial not only to provide engagement but to improve the quality of care. The major challenge, however, in implementing caregiver engagement in stroke recovery is the power shift that may exist from shifting care from the medical professionals to the caregiver; arising from the decision-making authority and knowledge between the different stakeholders. Ultimately, it would be dependent on the caregiver, medical professional, and community support team to form effective partnerships; thereby promoting better engagement. In addition to the challenge of shifting the decision-making process, there is a significant gap in the literature regarding the 
opportunities and methodologies to promote active engagement in stroke recovery. The limited guidance leads to constraints regarding the effective means to encourage engagement and ensure the practices implemented are meaningful for the different stakeholders. One possible solution would be to consider the generic guidelines available in the literature and tailor it based on the requirements of stroke recovery. However, this would require active collaboration and participation between the various stakeholders involved in recovery.

\section{CONCLUSION}

Caregiver engagement in stroke that is targeted to the different levels of care have the potential to reduce unmet needs and promote interaction with medical professional in an on-going basis. However, this would require the formation of relationships between the various stakeholders in recovery. Hence, there is a need to include public health policies that can promote caregiver engagement; especially in countries such as Denmark and Australia, where the primary focus of stroke care occurs within the community. Furthermore, there is a need for theoretical and practical evidence to highlight the potential of caregiving engagement in improving quality of care outcomes for the person living with stroke.

\section{REFERENCES}

1. Krishnamurthi RV, Ikeda T, Feigin VL. Global, Regional and country-specific burden of ischaemic stroke, intracerebral haemorrhage and subarachnoid haemorrhage: a systematic analysis of the Global Burden of Disease Study 2017. Neuroepidemiology. (2020) 54:171-9. doi: 10.1159/000506396

2. Feigin VL, Norrving B, George MG, Foltz JL, Roth GA, Mensah GA. Prevention of stroke: a strategic global imperative. Nat Rev Neurol. (2016) 12:501-12. doi: 10.1038/nrneurol.2016.107

3. Rajsic S, Gothe H, Borba HH, Sroczynski G, Vujicic J, Toell T, et al. Economic burden of stroke: a systematic review on post-stroke care. Eur J Health Econ. (2019) 20:107-34. doi: 10.1007/s10198-018-0984-0

4. Feigin VL, Nguyen G, Cercy K, Johnson CO, Alam T, Parmar PG, et al. Global, regional, and country-specific lifetime risks of stroke, 1990 and 2016. N Engl J Med. (2018) 379:2429-37. doi: 10.1056/NEJMoa1804492

5. Katan M, Luft A. Global burden of stroke. Semin Neurol. (2018) 38:208-11. doi: 10.1055/s-0038-1649503

6. Low LF, Yap M, Brodaty H. A systematic review of different models of home and community care services for older persons. BMC Health Serv Res. (2011) 11:93. doi: 10.1186/1472-6963-11-93

7. Pucciarelli G, Lommi M, Magwood GS, Simeone S, Colaceci S, Vellone E, et al. Effectiveness of dyadic interventions to improve stroke patient-caregiver dyads' outcomes after discharge: a systematic review and meta-analysis study. Eur J Cardiovasc Nurs. (2021) 20:14-33. doi: 10.1177/1474515120926069

8. Tsai PC, Yip PK, Tai JJ, Lou MF. Needs of family caregivers of stroke patients: a longitudinal study of caregivers' perspectives. Patient Prefer Adherence. (2015) 9:449-57. doi: 10.2147/PPA.S77713

9. Hekmatpou D, Mohammad Baghban E, Mardanian Dehkordi L. The effect of patient care education on burden of care and the quality of life of caregivers of stroke patients. J Multidiscip Healthc. (2019) 12:211-7. doi: 10.2147/JMDH.S196903

10. Gertrude N, Kawuma R, Nalukenge W, Kamacooko O, Yperzeele L, Cras $\mathrm{P}$, et al. Caring for a stroke patient: the burden and experiences of primary caregivers in Uganda - a qualitative study. Nurs Open. (2019) 6:1551-8. doi: $10.1002 /$ nop 2.356

11. Suneerat B, Aporn D, Chintana W. Factors influencing the burden of family caregiving for survivors of stroke. Pac Rim Int J Nurs Res. (2021) 25:102-13.

\section{DATA AVAILABILITY STATEMENT}

The original contributions presented in the study are included in the article/supplementary material, further inquiries can be directed to the corresponding author/s.

\section{AUTHOR CONTRIBUTIONS}

EL initiated this study to identify the models of care in stroke recovery, the contributions of the various stakeholders in ensuring efficient care to the person living with stroke using evidence-based perspectives, and performed this study under the supervision of AF and SI. Further, EL drafted the manuscript that was revised by AF, SI, LR, PL, FK, $\mathrm{MA}$, and JG. All authors approved the final version of the manuscript.

\section{FUNDING}

This study was supported through doctoral scholarships from the School of Information Technology, Deakin University, and the Department of Public Health, University of Copenhagen. JG was supported by an Australian Research Council Laureate Fellowship FL190100035.

12. Lobo EH, Frølich A, Abdelrazek M, Rasmussen LJ, Grundy J, Livingston $\mathrm{PM}$, et al. Information, involvement, self-care and support - the needs of caregivers of people with stroke: a grounded theory approach. medRxiv. (2021). doi: 10.1101/2021.10.06.21264603

13. Camak DJ. Addressing the burden of stroke caregivers: a literature review. J Clin Nurs. (2015) 24:2376-82. doi: 10.1111/jocn.12884

14. Lopez-Bastida J, Oliva Moreno J, Worbes Cerezo M, Perestelo Perez L, Serrano-Aguilar P, Montón-Álvarez F. Social and economic costs and healthrelated quality of life in stroke survivors in the Canary Islands, Spain. BMC Health Serv Res. (2012) 12:315. doi: 10.1186/1472-6963-12-315

15. Taylor TN, Davis PH, Torner JC, Holmes J, Meyer JW, Jacobson MF. Lifetime cost of stroke in the United States. Stroke. (1996) 27:1459-66. doi: 10.1161/01.STR.27.9.1459

16. Pucciarelli G, Rebora P, Arisido MW, Ausili D, Simeone S, Vellone E, et al. Direct cost related to stroke: a longitudinal analysis of survivors after discharge from a rehabilitation hospital. J Cardiovasc Nurs. (2020) 35:86-94. doi: 10.1097/JCN.0000000000000620

17. Pucciarelli G, Ausili D, Galbussera AA, Rebora P, Savini S, Simeone S, et al. Quality of life, anxiety, depression and burden among stroke caregivers: a longitudinal, observational multicentre study. J Adv Nurs. (2018) 74:1875-87. doi: $10.1111 /$ jan.13695

18. Cadilhac DA, Sheppard L, Kim J, Tan E, Gao L, Sookram G, et al. Economic evaluation protocol and statistical analysis plan for the costeffectiveness of a novel Australian stroke telemedicine program; the Victorian Stroke Telemedicine (VST) program. Front Neurol. (2020) 11:602044. doi: 10.3389/fneur.2020.602044

19. Ganapathy V, Graham GD, Dibonaventura MD, Gillard PJ, Goren A, Zorowitz RD. Caregiver burden, productivity loss, and indirect costs associated with caring for patients with poststroke spasticity. Clin Interv Aging. (2015) 10:1793-802. doi: 10.2147/CIA.S91123

20. Haley WE, Marino VR, Sheehan OC, Rhodes JD, Kissela B, Roth DL. Stroke survivor and family caregiver reports of caregiver engagement in stroke care. Rehabil Nurs. (2019) 44:302-10. doi: 10.1097/rnj.0000000000000100

21. Barello S, Castiglioni C, Bonanomi A, Graffigna G. The Caregiving Health Engagement Scale (CHE-s): development and initial validation of a new questionnaire for measuring family caregiver engagement in healthcare. $B M C$ Public Health. (2019) 19:1562. doi: 10.1186/s12889-019-7743-8 
22. Lutz BJ, Young ME, Cox KJ, Martz C, Creasy KR. The crisis of stroke: experiences of patients and their family caregivers. Topics stroke Rehabil. (2011) 18:786-97. doi: 10.1310/tsr1806-786

23. Coyne E, Dieperink KB, Østergaard B, Creedy DK. Strengths and resources used by Australian and Danish adult patients and their family caregivers during treatment for cancer. Eur J Oncol Nurs. (2017) 29:53-9. doi: 10.1016/j.ejon.2017.05.005

24. Overgaard C. Cultures of volunteer care? A comparative study of Australia and Denmark. Int J Care Caring. (2020) 4:183-99. doi: 10.1332/239788220X15833754718034

25. Schulz E. Impact of ageing on long-term care workforce in Denmark. In: NEUJOBS Working Paper. Berlin (2014).

26. Lynch EA, Mackintosh S, Luker JA, Hillier SL. Access to rehabilitation for patients with stroke in Australia. Med J Aust. (2019) 210:21-6. doi: $10.5694 / \mathrm{mja} 2.12034$

27. Gbiri CA, Olawale OA, Isaac SO. Stroke management: informal caregivers' burdens and strians of caring for stroke survivors. Ann Phys Rehabil Med. (2015) 58:98-103. doi: 10.1016/j.rehab.2014.09.017

28. Nøhr C, Parv L, Kink P, Cummings E, Almond H, Nørgaard JR, et al. Nationwide citizen access to their health data: analysing and comparing experiences in Denmark, Estonia and Australia. BMC Health Serv Res. (2017) 17:534. doi: 10.1186/s12913-017-2482-y

29. Singh K, Meyer SR, Westfall JM. Consumer-facing data, information, and tools: self-management of health in the digital age. Health Aff (Millwood). (2019) 38:352-8. doi: 10.1377/hlthaff.2018.05404

30. Bennett WL, Pitts S, Aboumatar H, Sharma R, Smith BM, Das A, et al. AHRQ comparative effectiveness technical briefs. In: Strategies for Patient, Family, Caregiver Engagement. Rockville, MD: Agency for Healthcare Research and Quality (US) (2020). p. 1-2.

31. Carman KL, Dardess P, Maurer M, Sofaer S, Adams K, Bechtel C, et al. Patient and family engagement: a framework for understanding the elements and developing interventions and policies. Health Aff (Millwood). (2013) 32:223-31. doi: 10.1377/hlthaff.2012.1133

32. Hill NL, Yevchak A, Gilmore-Bykovskyi A, Kolanowski AM. The Model of Care Partner Engagement: use in delirium management. Geriatr Nurs. (2014) 35:272-8. doi: 10.1016/j.gerinurse.2014.02.023

33. King RB, Ainsworth CR, Ronen M, Hartke RJ. Stroke caregivers: pressing problems reported during the first months of caregiving. J Neurosci Nurs. (2010) 42:302-11. doi: 10.1097/JNN.0b013e3181f8a575

34. Hartford W, Lear S, Nimmon L. Stroke survivors' experiences of team support along their recovery continuum. BMC Health Serv Res. (2019) 19:723. doi: 10.1186/s12913-019-4533-z

35. Aadal L, Pallesen H, Arntzen C, Moe S. Municipal cross-disciplinary rehabilitation following stroke in Denmark and Norway: a qualitative study. Rehabil Res Pract. (2018) 2018:1972190. doi: 10.1155/2018/1972190

36. White JH, Magin P, Pollack MR. Stroke patients experience with the Australian health system: a qualitative study. Can J Occup Ther. (2009) 76:81-9. doi: 10.1177/000841740907600205

37. AIHW. How does Australia's health system work? In: Australia's Health 2016. Canberra: Australian Institute of Health and Welfare (2016). p. 23-24.

38. Forde I, Nader C, Socha-Dietrich K, Oderkirk J, Colombo F. Primary Care Review of Denmark. Paris: Organisation for Economic Co-operation Development (2016). p. 6-16.

39. Douw K, Nielsen CP, Pedersen CR. Centralising acute stroke care and moving care to the community in a Danish health region: challenges in implementing a stroke care reform. Health Policy. (2015) 119:1005-10. doi: 10.1016/j.healthpol.2015.05.007

40. Schulz E. The Long-Term Care System in Denmark. Contribution To Wp 1 Of The Ancien Project: Enepri Research Report No. 73. (2010). Available online at: https://www.files.ethz.ch/isn/122389/Denmark.pdf (accessed November 27, 2020).

41. Stroke Foundation. Clinical Guidelines for Stroke Management. (2018). Available online at: https://files.magicapp.org/guideline/20bb1bd1-c608437d-8be9-9455b5a2c310/published_guideline_2282-5_2.pdf (accessed November 29, 2020).

42. Doser K, Norup A. Caregiver burden in Danish family members of patients with severe brain injury: the chronic phase. Brain Inj. (2016) 30:334-42. doi: $10.3109 / 02699052.2015 .1114143$
43. Kitter B. Support Needs of Carers. Synapse Bridge Magazine (2015). Available online at: https://strokefoundation.org.au/Blog/2015/05/14/Support-needsof-carers (accessed November 27, 2020).

44. Hastrup S, Johnsen SP, Terkelsen T, Hundborg HH, Von WeitzelMudersbach P, Simonsen CZ, et al. Effects of centralizing acute stroke services: a prospective cohort study. Neurology. (2018) 91:e236-e48. doi: 10.1212/WNL.0000000000005822

45. Perry L, Middleton S. An investigation of family carers' needs following stroke survivors' discharge from acute hospital care in Australia. Disabil Rehabil. (2011) 33:1890-900. doi: 10.3109/09638288.2011.553702

46. Pallesen H, Aadal L, Moe S, Arntzen C. Gateway to recovery: a comparative analysis of stroke patients' experiences of change and learning in Norway and Denmark. Rehabil Res Pract. (2019) 2019:1726964. doi: 10.1155/2019/1726964

47. Dewey HM, Thrift AG, Mihalopoulos C, Carter R, Macdonell RA, Mcneil JJ, et al. Informal care for stroke survivors: results from the North East Melbourne Stroke Incidence Study (NEMESIS). Stroke. (2002) 33:1028-33. doi: 10.1161/01.STR.0000013067.24300.B0

48. Kuluski K, Kokorelias KM, Peckham A, Goldhar J, Petrie J, Alloway CA. Twelve principles to support caregiver engagement in health care systems and health research. Patient Experience J. (2019) 6:141-8. doi: $10.35680 / 2372-0247.1338$

49. Given B, Sherwood PR, Given CW. What knowledge and skills do caregivers need? Am J Nurs. (2008) 108:28-34; quiz 34. doi: 10.1097/01.NAJ.0000336408.52872.d2

50. Essue BM, Jowsey T, Jeon YH, Mirzaei M, Pearce-Brown CL, Aspin C, et al. Informal care and the self-management partnership: implications for Australian health policy and practice. Aust Health Rev. (2010) 34:414-22. doi: 10.1071/AH09795

51. Pindus DM, Mullis R, Lim L, Wellwood I, Rundell AV, Abd Aziz NA, et al. Stroke survivors' and informal caregivers' experiences of primary care and community healthcare services - a systematic review and meta-ethnography. PLoS One. (2018) 13:e0192533. doi: 10.1371/journal.pone.0192533

52. Adeoye O, Nyström KV, Yavagal DR, Luciano J, Nogueira RG, Zorowitz $\mathrm{RD}$, et al. Recommendations for the establishment of stroke systems of care: a 2019 update. Stroke. (2019) 50:e187-e210. doi: 10.1161/STR.00000000000 00173

53. Wright L, Hill KM, Bernhardt J, Lindley R, Ada L, Bajorek $\mathrm{BV}$, et al. Stroke management: updated recommendations for treatment along the care continuum. Intern Med J. (2012) 42:562-9. doi: 10.1111/j.1445-5994.2012.02774.x

54. Australian Commission on Safety and Quality in Health Care. Acute Stroke Clinical Care Standard - Evidence Sources. Sydney: ACSQHC (2019).

55. Arntzen C, Moe S, Aadal L, Pallesen H. Facilitating learning and change in the daily lives of stroke survivors: a comparative analysis of municipal stroke rehabilitation services in Norway and Denmark. Cogent Med. (2019) 6:1608080. doi: 10.1080/2331205X.2019.1608080

56. Australian Government. Disability and Carers. (2020). Available online at: https://www.dss.gov.au/disability-and-carers/carers (accessed November $29,2020)$.

Conflict of Interest: The authors declare that the research was conducted in the absence of any commercial or financial relationships that could be construed as a potential conflict of interest.

Publisher's Note: All claims expressed in this article are solely those of the authors and do not necessarily represent those of their affiliated organizations, or those of the publisher, the editors and the reviewers. Any product that may be evaluated in this article, or claim that may be made by its manufacturer, is not guaranteed or endorsed by the publisher.

Copyright $\odot 2021$ Lobo, Abdelrazek, Grundy, Kensing, Livingston, Rasmussen, Islam and Frølich. This is an open-access article distributed under the terms of the Creative Commons Attribution License (CC BY). The use, distribution or reproduction in other forums is permitted, provided the original author(s) and the copyright owner(s) are credited and that the original publication in this journal is cited, in accordance with accepted academic practice. No use, distribution or reproduction is permitted which does not comply with these terms. 